\title{
Formação de educadores e contexto de trabalho: contribuições da investigação-ação às práticas educativas- assistenciais
}

Leandro Rogério Pinheiro

Universidade do Vale do Rio dos Sinos

\section{Resumo}

Este ensaio apresenta resultados de uma pesquisa realizada com coordenadores de um centro educativo-assistencial de Porto Alegre, o Centro de Promoção da Criança e do Adolescente (CPCA), localizado no bairro Lomba do Pinheiro, em um contexto em que crianças e adolescentes têm fortes referências pedagógicas e sócio-simbólicas nas relações que constroem com os educadores dessa entidade. Propondo-se problematizar 'como a formação dos educadores influencia nas práticas educativas desenvolvidas com os educandos', o trabalho está sendo realizado na perspectiva da investigação-ação, com apoio em técnicas de observação, mapeamentos relacionais e entrevistas, visando conhecer as trajetórias de vida dos sujeitos e caracterizar o contexto de trabalho construído na organização. Nesse ínterim, as inferências construidas assinalam que os educadores, de um lado, estabelecem relações fortemente pautadas na 'proteção' dos educandos e, de outro, estimulam práticas pouco emancipatórias e bastante hierarquizantes em relação à comunidade onde atuam. As informações elaboradas têm se orientado à problematização dos referenciais pedagógicos praticados no cotidiano, no intuito de estimular a produção de novas relações socioeducativas.

\section{Palavras-chave}

Formação - Trabalho - Auto-eco-organização - Investigação-ação. 


\title{
Formation of educators and work context: contribution of action-investigation to supportive-educative practices
}

\author{
Leandro Rogério Pinheiro \\ Universidade do Vale do Rio dos Sinos
}

\begin{abstract}
This essay presents results of a research carried out with the coordinators of a social assistance and educational center in Porto Alegre (Brazil) - Center for the Promotion of the Child and Adolescent (CPCA) - located in the borough of Lomba do Pinheiro, an environment where children and teenagers build strong pedagogical and socio-symbolical references based on the relationships developed with the Center's educators. With the aim of problematizing "how the educators' formation influences the educative practices conducted with the educated", the work is carried out under the perspective of action-investigation with the support of observation techniques, relational maps and interviews, seeking to learn about the life trajectories of the subjects and to characterize the work context constructed in the organization. At the same time, the inferences constructed point out that the educators establish relationships strongly based on the "protection" of the educated, encourage practices that are not emancipative, and stimulate hierarchy with respect to the community. The information organized here has been oriented to problematize the pedagogical framework routinely employed, with the purpose of encouraging the production of new socioeducative relations.
\end{abstract}

\section{Keywords}

Formation - Work - Auto-eco-organization - Action-investigation.

\footnotetext{
Contact:
}

Leandro Rogério Pinheiro

Rua Anápio Gomes, 924 apto. 202

94010-010 - Gravataí - RS

e-mail: leandrop@faccat.br 
A atuação de instituições educativasassistenciais na cidade de Porto Alegre comporta o convívio com elevados graus de vulnerabilidade social, considerando, aqui, os baixos níveis de renda, a reduzida escolarização e os elevados índices de violência. Dados do Instituto Brasileiro de Geografia e Estatística (IBGE, 2000) indicam que os percentuais de alfabetização e escolarização possuem uma tendência descendente na medida que se precarizam as condições de subsistência da família. No mesmo sentido, Ramos (2004) assinala que o número de mortes por armas de fogo é superior entre jovens pobres e negros. Aspectos de um cenário que, embora concernente ao contexto brasileiro de forma mais ampla, relacionam-se com o cotidiano dos educadores com quem dialoguei nesta pesquisa.

As problematizações que proponho neste trabalho partem de uma investigação numa organização não governamental (ONG), o Centro de Promoção da Criança e do Adolescente (CPCA), com sede e atuante na Lomba do Pinheiro, região bastante empobrecida de Porto Alegre. Essa organização atua no desenvolvimento de programas socioeducativos, visando viabilizar o acesso a direitos sociais (como educação, saúde, trabalho etc.) previstos no Estatuto da Criança e do Adolescente (ECA).

As crianças e os adolescentes que participam das oficinas de aprendizagem demonstram atribuir significativa importância a seus relacionamentos com os coordenadores pedagógicos do CPCA, com quem estamos construindo a investigação-ação que relatarei aqui. Assim, tomando como situação-problema a questão 'como a formação dos educadores influencia nas práticas educativas desenvolvidas com os educandos?', iniciamos um processo reflexivo acerca das relações constituídas e dos referentes sociopedagógicos praticados no cotidiano de trabalho, no intuito de contribuir às atividades desenvolvidas pela instituição.

Para expor o caminho trilhado, organizei este texto por uma exposição inicial do contexto de trabalho no CPCA, seguido do posicionamento teórico-metodológico na investigação. Depois, trago uma análise das informações construídas até o momento, passando, enfim, às problematizações propostas para a continuidade da investigação.

\section{Sobre o CPCA e seu entorno: um contexto de trabalho}

O CPCA foi criado no final dos anos 1970 por iniciativa de freis que atuavam na Lomba do Pinheiro. Inicialmente era uma creche para filhos de trabalhadores. Entre os registros que encontrei, um reordenamento institucional já em meados da década de 1990 teria sido uma experiência rupturante. Assim, em decorrência de uma mudança extensiva à assistência social em Porto Alegre, com base no ECA e na Legislação Orgânica de Assistência Social (LOAS), o CPCA passou a atuar com base em programas sociais e metas de atendimento, destinados a populações empobrecidas da cidade. Guardadas as modificações ocorridas ao longo do tempo, a consecução de programas ainda representa a estrutura básica de funcionamento da organização.

A entidade, sediada na parada 10 da Lomba do Pinheiro', possui uma relação de cooperação com a comunidade, cedendo o espaço para reuniões e atividades culturais. Os coordenadores chegam a afirmar que ela é referência na sua área de atuação na região. 0 CPCA, todavia, não parece ser uma organização destinada à expressão política dos moradores da Lomba, estabelecendo muito antes uma relação de prestadora de serviços, embora os educadores se mostrem bastante implicados em colaborar para a melhoria das condições de vida dos educandos e suas famílias.

Quando nos direcionamos à realidade da Lomba do Pinheiro, situamo-nos numa região semi-urbanizada, cortada por uma rodovia central, que delinea a região. Em geral, as localidades próximas à via principal são mais bem-servidas, com sistemas de esgoto, água, rede elétrica e transporte público. Além disso, as moradias são

1. Usualmente, a população da Lomba do Pinheiro relaciona a distribuição geográfica das moradias e dos estabelecimentos na comunidade ao sistema de pontos de transporte público da principal via de acesso da região, a Estrada João de Oliveira Remião. Tal referência carregaria, então, a localização e o dimensionamento das distâncias entre os habitantes. 
mais bem-acabadas e seguras. No entanto, quando nos afastamos da rodovia e entramos nas 'vilas', como costumam designar os educadores, encontramos ocupações clandestinas em situações de risco, com rede elétrica improvisada, serviços públicos precários, degradação ambiental e uma população com reduzido grau de escolaridade e baixos níveis de renda.

As ocupações tiveram um incremento a partir dos anos 1970, quando a região se torna opção de migrantes que chegam à capital do estado em busca de trabalho. Hoje, são aproximadamente 54 mil habitantes, numa comunidade com tradição de reivindicação e organização popular (Oliveira, 2004).

Nas consultas aos coordenadores do CPCA, no que concerne à relação com crianças e adolescentes, foram relatados dois conjuntos de ação principais na comunidade. É necessário aprofundar a investigação sobre a composição destas e de demais redes de ação na Lomba do Pinheiro, mas cabe aqui citar os casos que compõem a interpretação de cenário desses educadores.

De um lado, teríamos a rede de pública de assistência e de educação, articulando Estado e ONG conveniadas que, por seu turno, mantêm relações (ainda que fragéis) com escolas e associações de bairro. Esse conjunto trabalharia tendo como referente central os direitos previstos no ECA. De outro lado, a rede de tráfico de drogas, a exploração sexual e o trabalho infantil, cuja estrutura relacional é pouco conhecida, embora se reconheça que haja laços de cooperação entre moradores dos bairros (educandos e pais de educandos) e as lideranças do tráfico, em função da proteção e das fontes de subsídio que estas ofereceriam nas 'vilas'.

\section{Sobre o trabalho dos educadores}

Passando aos serviços desenvolvidos pelo CPCA, poderia dizer que a prática dos educadores se materializa numa rotina de oficinas de aprendizagens diárias, vinculadas a programas socioeducativos municipais. No caso específico de crianças e adolescentes, seriam dois programas principais: o Serviço de Apoio Sócio-Educativo (SASE) e o Trabalho Educativo (TE). A primeira modalidade prevê o envolvimento de crianças $\mathrm{e}$ adolescentes de 7 a 14 anos em atividades pedagógicas e recreativas em turno inverso ao da escola. Já o TE objetiva a iniciação sociolaboral de educandos de 15 a 18 anos.

As oficinas oferecidas aos educandos envolvem temas diversos, numa escala de faixa etária. No SASE, são: atividades lúdicas; artesanato; e esporte. No TE, são: culinária e informática. As oficinas são complementadas, ainda, por atividades extras, para facilitar a integração dos educandos. Entre esses e outros serviços, totalizam aproximadamente 500 assistidos em turnos matutino e vespertino.

Mesmo que as atividades disponibilizem conhecimentos técnicos aos educandos ou estejam pautadas pelo labor/fazer, o interesse principal no trabalho com crianças e adolescentes está na acolhida e na criação de vínculos que não só garantam a permanência dos assistidos, mas possibilitem uma relação propícia ao desenvolvimento deles: o vínculo ambientaria relações de confiança que abririam espaço a formação de hábitos, costumes, prioridades. Em síntese, embora não possuam uma grade de disciplinas relativamente fixa, a exemplo da prática escolar, tais programas possuem um conjunto de conteúdos e propósitos educativos, organizado em torno das habilidades estimuladas nas oficinas e da construção de hábitos nas relações educando-educador ${ }^{2}$.

Além disso, em função do contexto de atuação, o CPCA seria um espaço de acolhida, seja porque os pais não podem permanecer com os filhos e precisam trabalhar, seja porque a família não comporta laços acolhedores. A influência educativa estaria mais no convívio, no estruturar de tempos, nas prioridades, nas formas de se relacionar, que os coordenadores pedagógicos situam como "crescimento dos educandos".

2. Como exemplo, assinalaria que as práticas educativas do CPCA envolvem, além do aprendizado de técnicas de artesanato, culinária etc., a formação de hábitos de higiene e alimentação e de certa disciplina com horários. Os educandos que freqüentam a ONG passam, normalmente, por uma sequência diária que inclui higiene pessoal, refeições e práticas recreativas e/ou produtivas em grupo. 
Os funcionários do CPCA são, na maioria dos casos, pessoas com $3^{\circ}$ grau (completo ou cursando) - oriundos das áreas de Psicologia, Serviço Social, Educação Física, TeologiaFilosofia e Pedagogia - e também alguns com Ensino Fundamental ou Médio. Todos são denominados educadores sociais e recebem uma remuneração semelhante, com exceção de coordenadores pedagógicos e técnicas (psicóloga e assistente social), cujos salários são superiores à média organizacional.

A gestão é conduzida por quatro educadores, que acumulam coordenação pedagógica e administração financeira da entidade. O CPCA está constituido por um quadro funcional de 4 freis, 3 estagiários e 25 funcionários contratados, distribuídos e itinerantes entre 3 entidades: Casa São Francisco, Casa de Acolhida e Sede. Nessa última, onde está em curso a pesquisa, são 20 educadores sociais atuantes, incluindo 4 coordenadores, 2 técnicas, 3 auxiliares de cozinha e 11 facilitadores de oficinas.

Trata-se de um espaço com maioria de pedagogos e professores de Educação Física, cujas atribuições, pelo observado, exigem a atuação em circunstâncias formativas que, para além dos conteúdos das oficinas, constituam hábitos e costumes. Nesse sentido, o discurso dos educadores situa, de um lado, a criação de vínculos/proteção da criança e, de outro, a emancipação do educando.

Nesse interim, a pesquisa tem sido desenvolvida, sobretudo, com os coordenadores pedagógicos, cujos posicionamentos afetam tanto as diretrizes pedagógicas quanto os encaminhamentos da gestão da ONG, influenciando atividades educativas específicas e organização do espaço de trabalho e convívio. Assim, podemos nos perguntar o que entendemos por 'proteção' e 'emancipação', como referentes citados freqüentemente nas práticas do CPCA.

Partimos do pressuposto de que a formação dos educadores, articulado ao contexto de trabalho que constroem, influencia na condução das atividades junto com os educandos. Dessa forma, o caminho trilhado até aqui buscou concretizar um processo reflexivo (ainda inicial), cujos resultados apresentarei mais adiante. Antes de relatar a análise dos dados que construímos até o momento, caracterizando as práticas dos coordenadores e o ambiente de trabalho produzido entre educadores, creio que seria relevante resumir as referências teóricas e os passos dados na investigação.

\section{Pontos de partida e trilhas construídas}

A pesquisa que relato foi desencadeada em decorrência de minha vinculação a um programa de doutorado, almejando realizar uma investigação que, além de promover uma imersão etnográfica, colaborasse com os sujeitos da comunidade pesquisada. Nesse sentido, a aproximação às contribuições de Morin (1996; 2001) e Villasante (2002) vem sendo uma importante inspiração para problematizar as articulações entre a formação dos sujeitos e suas tomadas de posição no contexto de trabalho, além de indicar-me caminhos a trilhar na colaboração com os educadores do CPCA.

A noção de auto-eco-organização, especificamente, tem sido uma referência reflexiva central. Essa proposição designaria uma relação complementar-contraditória constituinte dos sujeitos sociais, "[...] que desenvolvem sua autonomia na dependência ${ }^{3}$ de sua cultura - e para as sociedades - que se desenvolvem na dependência de seu meio [...]" (Morin, 2001, p. 95). Assim, meu diálogo com coordenadores pedagógicos, por exemplo, vem sendo instigado a observar as interações na comunidade organizacional e a configuração do contexto de trabalho, mas sobretudo considerando cada sujeito na compreensão dos posicionamentos que assumem, dos saberes que dispõem nas relações.

Dessa maneira, assumi como ênfase refletir as relações construídas (entre sujeitos; entre sujeitos e meio produzido). Morin (1996) propõe evitarmos a conotação de objeto em favor da noção de sistema que, dotado de algum tipo de organização, estrutura-se relacionalmente. E para

3. Grifo (itálico) realizado por mim, para destaque nas elaborações deste artigo. 
efeito desta investigação, significa conceber a formação dos sujeitos por meio das interações e práticas sociais que compartilham/produzem em suas trajetórias e, ademais, contemplar o sujeito (constituído/constituinte nas relações) como construtor de domínios explicativos próprios e, por conseguinte, de tomadas de posição relativamente autônomas em relação ao vivido nos espaços sociais onde atua.

Assim, esta pesquisa assume como pressuposto que a formação é uma prática construída social e historicamente, em diversas modalidades e intencionalidades, e que

\section{[...] implica o reconhecimento das trajetórias} dos homens e mulheres, bem como exige a contextualização histórica destas trajetórias, assumindo a provisoriedade das propostas de determinada sociedade. (Batista, 2001, p. 136)

A perspectiva teórico-metodológica que procuro expressar neste texto, além de esboçar a compreensão das práticas dos educadores do CPCA de forma relacional, busca evidenciar que estar junto dos sujeitos significa instaurar uma nova relação no contexto pesquisado, e que esta constituirá então os resultados desta investigação: uma construção coletiva (parta ela de diretrizes participativas ou não), cujas peculiaridades são condizentes às alteridades dispostas.

Dessa forma, proponho tais condições à prática de investigação para dizer das dificultades e limitações dos discursos que construímos, embora mantenha o desejo de uma pesquisa comprometida em contribuir com a ONG onde atuamos. Nesse sentido, encontro nas palavras de Morin (1996) idéias que, para mim, são inquietantes: “[...] se existe um pensamento complexo, este não será um pensamento capaz de abrir portas, mas um pensamento onde estará sempre presente a dificuldade [...]” (p. 274).

\section{Trilhas construídas}

Passando ao caminho trilhado, a pesquisa iniciou por uma imersão no contexto pesquisado, de modo a interagir com as práticas e regras internas, as redes de amizade e os laços de solidariedade no contexto de trabalho do CPCA. Para começar, desejava fazer uma descrição de inspiração etnográfica. Orientado por Villasante (2002), procurava conhecer a organização relacional no CPCA, visando problematizar, depois, as práticas junto com os educadores.

0 conteúdo desses movimentos populares no imediato e manifesto mostra uma reivindicação ou uma atuação concreta que parece ser onde o sentido do movimento se centra e esgota. Porém, há muito mais, porque essa política, além de alcançar o seu fim, está educando e socializando aos setores populares em jogo de alianças ou de corporativismo. (p. 33-34)

Villasante (2002) pretende aportar pressupostos e técnicas para uma investigação-ação que estimule a criatividade comunitária. Dessa forma, encontrei em suas publicações algumas idéias para planejar a pesquisa que relato, concebendo momentos de reconhecimento e integração à comunidade investigada e, também, técnicas para devoluções reflexivas que instiguem o planejamento de novas práticas educativas.

A pesquisa começou efetivamente em setembro de 2005, quando passei a freqüentar a sede do CPCA, permanecendo dias inteiros na ONG, entre conversas com os coordenadores pedagógicos e a observação da rotina de trabalho. Procurei ir a campo aberto para conhecer as pessoas e seu jeito de trabalhar.

Tinha em mente os pressupostos que relatei acima, mas, por outro lado, buscava contemplar as situações-problema dispostas no contexto e, desses pontos, trazer novas leituras e categorizações: esse ir e vir entre práticas e teorias vem colaborando para que compreenda o contexto de atuação da ONG e, dessa forma, possa aportar reflexões sobre o cotidiano dos educadores.

Depois de dois meses de imersão, tinha construído com os coordenadores pedagógicos informações sobre o funcionamento básico do CPCA, condições de contratação, titulação e ori- 
gem dos educadores e características das relações entre colegas (amizades, laços de solidariedade).

Na sequência, a observação e os registros desses aspectos permaneceu em curso, mas de maneira complementar a uma fase mais dirigida, quando busquei considerar: condição socioeconômica das localidades de onde advinham os educandos; posicionamento do CPCA na Lomba do Pinheiro; trajetória de vida dos coordenadores pedagógicos; e posicionamentos práticos destes em situações práticas específicas (como reuniões de equipe, por exemplo) ${ }^{4}$.

As técnicas utilizadas têm sido: a observação, pela qual descrevo acontecimentos cotidianos e participo de atividades, colaborando em serviços que precisem (presenciar reuniões, lavar louça, empacotar presentes, co-elaborar critérios avaliativos etc.); as entrevistas em profundidade com coordenadores pedagógicos, quando busquei trajetórias de vida e opiniões sobre temas de trabalho; e a construção de sociograma e organograma, para que os sujeitos representam graficamente seu entendimento das relações no seu campo de atuação.

Quando elaborei os roteiros para entrevistas com os quatro coordenadores, parti dos registros de diário de campo. Elenquei uma série de perguntas que me oportunizassem narrativas sobre: história do CPCA; compreensão do gestor sobre sua relação com o CPCA e aprendizagens daí resultantes; opinião sobre temas gerais referentes ao campo de ação da ONG ( $3^{\circ}$ setor, crianças e adolescentes, comunidade); e, como já citado, trajetória dos coordenadores. Preocupado com que a entrevista não fosse demasiadamente estruturada, dispus palavras-chave para que falassem instigados por expressões de seu trabalho/convívio (CPCA; Lomba do Pinheiro; trabalho; educando/educador).

Ao final das entrevistas, pedia ao entrevistando que desenhasse um esquema com seu entendimento da distribuição das atribuições/responsabilidades na equipe da ONG. Assim, tinha mais um registro para refletir as hierarquizações e prioridades estabelecidas pelos gestores quando se referiam às relações internas no CPCA.
Denominei esse registro de organograma, numa referência ao esquema convencional de distribuição hierárquica em organizações, embora reconheça as distinções entre os dois tipos de gráfico. Buscava criar um registro complementar para conhecer a visão de cada coordenador para, inclusive, oportunizar um contraste entre as posições individuais (e, ademais, não me fixar apenas no organograma institucional), numa referência metodológica à noção de auto-eco-organização.

Finalizando essa etapa de pesquisa, já em janeiro de 2006, construímos (entre gestores e investigador) um sociograma sobre o tema de assistência a crianças e adolescentes, tendo como delimitação geográfica a região da Lomba do Pinheiro. De um lado, a reunião trouxe a interpretação dos coordenadores pedagógicos sobre que sujeitos sociais atuam na área de abrangência de atendimento da ONG, distribuídos num plano conforme eixos de poder de influência e afinidade com a proposta pedagógica do $\mathrm{CPCA}^{5}$. Assim, foram situados associações de bairro, educandos, pais de educandos, gestão municipal, escolas, outras ONGs etc. Nesse momento, estava bastante presente o dilema de conviver com a violência e o tráfico de drogas na realização do trabalho.

De outro lado, a construção do sociograma evidenciou conflitos, disputas e hierarquias entre os gestores, enunciando as relações de poder na organização que, como procurarei tratar mais adiante, possui um componente de gênero.

Ainda que essa etapa tenha se destinado mais ao estabelecimento de laços de confiança com os sujeitos e a construção de dados, posso afirmar que já está em curso um processo reflexivo, na medida em que as técnicas adotadas promovam a elaboração de explicações, o diálogo em novas bases de sistematização (vide o exemplo do sociograma, desconhecido para esses educadores), o questionamento sobre definições próprias sobre elementos do cotidiano, como a relação educando-educador.

4. A ênfase no trabalho com coordenadores pedagógicos se explica, nessa fase, por seu poder de influência tanto nas atividades educativas quanto na planificação organizacional, como já fora referido antes.

5. Mais informações sobre a elaboração de sociogramas, ver Martín (2003). 
Até o momento, esses foram os passos dados, delimitando-se mais à coleta de dados e momentos pontuais de problematização das práticas dos coordenadores pedagógicos. Posteriormente à sistematização das informações, iniciaremos uma nova fase, de devoluções e planejamentos, quando o processo reflexivo se acentuará. Na sequência do texto, apresentarei a análise das informações produzidas na primeira etapa, passando, depois, às técnicas propostas para sequência da pesquisa.

\section{Contexto de trabalho, formação e relação com educandos}

Neste tópico, apresentarei a análise das informações que produzimos até o momento. Restringirei o relato aos exemplos dos quatro coordenadores pedagógicos com quem trabalhei mais intensamente, buscando incluir na caracterização geral do contexto de trabalho as contribuições dos demais educadores do CPCA. Inicialmente, trarei uma descrição bastante sucinta das narrativas elaboradas pelos sujeitos sobre suas trajetórias e suas tomadas de posição no cotidiano organizacional.

Devo salientar que as narrativas foram construídas em entrevistas, cujos temas principais eram as características do ambiente de trabalho atual ou em meio a atividades laborais diárias, o que situa a perspectiva proposta aqui de construir depoimentos reflexivos desde o presente (de formação e auto-eco-organização).

Esto no implica que el pasado no sea de interés para lo cotidiano, lo es, pero no como trayectorias, sino como experiencias pasadas y sedimentadas bajo la forma de conocimiento incorporado y disponible en el presente, como conocimiento a la mano. (Lindón, 2000, p. 11)

\section{Sobre os sujeitos}

Pedro, frei e diretor geral da $\mathrm{ONG}^{6}$, quando relata sua trajetória, reforça sua origem interioriana ${ }^{7}$, assim como a importância de sua família, da religiosidade, dos estudos e do trabalho. Além disso, é elemento recorrente no trânsito de um lugar a outro em nome da causa doutrinária, assinalando militância e desapego pessoal (coerentes com a religiosidade franciscana).

[...] as pessoas acreditam aqui no trabalho, elas vêm buscar porque acham que aqui vão encontrar a resposta. Isso é bom; por outro lado, nos colocam um problema: 'ah, por que tu não atendeu minha situação?'. Ai, tu vai explicar, mas a pessoa não consegue entender os problemas numa perspectiva global [...].

[...] assim, os casos que nos chegam eles são casos difíceis [...]. Tem casos mais simples que o próprio grupo [equipe] vai 'curando', né [...]. (Pedro)

Esse coordenador exerce a articulação/conciliação na comunidade atendida e o faz numa postura assistencial-educativa hierarquizante. Posiciona-se como planificador e orientador na ONG, creditando o papel exercido à sua formação/ titulação e aos saberes que aporta (em psicopedagogia sobretudo). Poderia afirmar que, como gestor, expressa tomadas de posição conciliadoras (não conflitivas), embora reconheça as disputas do campo de atuação do CPCA.

Já Leonardo, responsável pela administração financeira e de departamento de pessoal, narra uma trajetória permeada pela expressão da origem e vida interiorana, pela ênfase no trabalho e na religiosidade e pelo trânsito por várias localidades. Essas características vêm acompanhadas ainda de certo apreço por empreendedorismo, de vivência de humildade e partilha e do incentivo ao estudo.

6. Os nomes atribuidos aos coordenadores neste texto são fictícios e têm a finalidade única de distinguir os sujeitos.

7. As referências que faço sobre as experiências de vida dos coordenadores pedagógicos no interior são relativas aos depoimentos elaborados por eles, que mencionaram terem nascido e vivido sua infância e adolescência em cidades distantes da capital do estado (Rio Grande do Sul) e onde as características culturais, segundo contam, diferem do lugar em que vivem e trabalham hoje. 
Poderia registrar, além disso, sua adesão ao discurso administrativo-empresarial. Distingue-se nas relações na organização por seus saberes técnico-administrativos e define o administrador como um solucionador de problemas e um conciliador devido aos conhecimentos que detém. Postula, muitas vezes, idéias socializadoras de educação (ensinar valores pelo testemunho). No entanto, fala de experiências pessoais importantes relacionadas à autonomia, ao aprender fazendo e ao empreendedorismo.

Luciana, junto com Márcia, desempenha a função institucional de coordenação pedagógica (embora, na prática diária, os quatro gestores a exerçam). Sua narrativa valoriza a origem e passagem pelo interior, não obstante tenha a experiência de vida urbana mais longa entre os gestores. Seu discurso também privilegia a relação com a família, a responsabilidade precoce do cuidado da irmã mais nova e certa resistência ao ambiente escolar ou de estudos. Numa sintese, afirmaria que Luciana destaca-se na equipe pelo afeto e pela sociabilidade. No trabalho, volta-se ao serviço educativo interno e operacional da entidade. Nesse ínterim, situa sua relação com o educando como crucial, estabelecendo uma interação com predomínio de fortes laços afetivos e de busca de proteção da criança e do adolescente.

Márcia, a mais recente integrante da gestão do CPCA (sete meses na coordenação), apresentou uma relação intensa e inquieta com os dogmas religiosos e os limites da função que exerce. Não obstante, é uma pessoa bastante disciplinada e comprometida com o trabalho. Expõe um gosto especial pelo estudo, pela sistematização de informações e pela reflexividade. Demonstra ser uma pessoa apegada aos amigos, à família, à religiosidade do exemplo franciscano (esteve prestes a optar pela vida de freira) e à suposta simplicidade de uma vida interiorana, condição em que viveu até a adolescência. A exemplo de Luciana, diria que Márcia posiciona-se como uma educadora voltada ao trabalho interno e operacional na ONG. É mais enfática que sua colega quando define sua atuação pelo cuidado com o educando.
[...] embora muitas pessoas não gostem dessa palavra cuidar, que a gente está aqui para educar e não para cuidar. Para mim, cuidar tem uma amplitude assim que inclui o educar também: cuidar as crianças que mais têm necessidade assim de um cuidado, que mais são negligenciadas assim [...]. (Márcia)

\section{Sobre o contexto}

Passemos às características do contexto assinaladas para essa problematização para, depois, trabalharmos as possiveis repercussões dos posicionamentos dos gestores e do contexto na relação estabelecida com o educando.

Um dos elementos a considerar é a expressão de religiosidade, seja por se tratar de ONG oriunda de uma iniciativa franciscana, seja pela importância manifestada pelos gestores. Embora não encontre grande adesão a cultos religiosos formais, percebo que há alguma congruência entre ideais religiosos franciscanos e a prática de assistência-educação, de forma que preceitos religiosos permaneçam presentes ainda que de forma discreta: como se as ações implementadas no CPCA buscassem referenciais ideológicos afins e, ao mesmo tempo, a religiosidade inspirasse uma forma de agir, num jogo recursivo.

Exemplo disso seria a frase cristã citada no folder do CPCA: "eu vim para que todos tenham vida em abundância". Não se trata de afirmar que tais ideais orientam a ação dos educadores (em muitos casos, há resistência aos cultos), mas sim observar que os postulados franciscanos encontram expressão na assistência praticada cotidianamente e, assim, podem se dispor à disputa por enunciação de motivos, razões etc.

Outro aspecto que constitui o contexto de trabalho é a proximidade com a violência e a pobreza da comunidade. 0 ambiente desenhado pelos gestores passa, muitas vezes, pela descrição de certa situação de emergências comunitárias. Nesse caso, é importante ressaltar que a maioria dos educandos são oriundos dos bairros mais pobres da Lomba do Pinheiro 
e, muitas vezes, não possuem recursos para comida ou transporte público: situação que posiciona tais subsídios como elementos significativos da relação com os assistidos. A pobreza, nesse sentido, ao mesmo tempo que se apresenta de forma constante, constituindo o cotidiano, instaura certa imprevisibilidade, na ausência do educando, na visita inesperada da família.

Outra condição que conturba a rotina de trabalho é a violência estabelecida nessa localidade, seja por causa da rede de tráfico e prostituição dos jovens, seja pelos casos de morte de educandos por uso de armas de fogo. Incidentes que desestruturam rotinas, lembram da urgência e complexidade do atendimento dos problemas, estressam, interpõem o imprevisível.

A gente costuma dizer que, quando a gente trabalha na área social, né se tu não tem um cuidado contigo e com as pessoas que trabalham, a gente acaba ficando doente [...]. 0 grau de violência que algunas histórias chegam para ti, o grau de fragilidade que as pessoas chegam [...]. É tudo falta, sabe? Tanto tiraram dessa pessoa e ele não tem mais nada [...]. (Luciana)

De outro lado, há uma ênfase nas relações interpessoais, demonstrada nos fortes laços de amizades e nas preocupações mútuas entre colegas. 0 afeto, o abraço, o estar-junto, o comer juntos são consideravelmente privilegiados pelos educadores. Além disso, em função do contexto de atuação, o CPCA é definido como um espaço de acolhida, seja porque os pais não podem ficar com os filhos e precisam trabalhar, seja porque a familia não comporta laços acolhedores: acolher o colega, o educando, o amigo seria uma prática organizadora da equipe na relação com o trabalho.

Crianças, adolescentes e juventude são sujeitos que precisam ser cuidados. (Márcia)

Outro item que permeia o trabalho é a condição de gênero. Na coordenação, ainda que as relações sejam bastante dialógicas, observo uma hierarquia bastante estruturada entre os integrantes da gestão. Há uma distinção entre coordenação pedagógica e setor administrativo, que compreende a direção geral e administração de departamento de pessoal e finanças: dois homens na administração, em sala fechada e exclusiva, e duas mulheres na coordenação pedagógica, num espaço aberto e de circulação.

A exemplo do que assinalam Holzmann (2000) e Salvaro (2004), o espaço educativo e do cuidado está dedicado e estruturado por mulheres, que oscilam no CPCA entre o gosto pelas relações afetuosas, o trânsito de educandos em seu espaço, e o desgaste de enfrentar diariamente os problemas da comunidade. De outro lado, o espaço decisório estratégico, embora conte com a colaboração feminina, é organizado predominantemente por homens.

Passando a outra característica, assinalaria que o trabalho no CPCA privilegia mais a dimensão cíclica do tempo do que a linear, embora ambas convivam. Há uma rotina de oficinas semanais e reuniões semanais, mensais ou semestrais. Além disso, há eventos periódicos no ano (por exemplo, planejamento em março e festividades de Natal em dezembro), de forma que transitamos entre ciclos mais ou menos extensos.

El calendario social otorga la seguridad y la certeza de la sucesión de puntos reconocibles, pero es en la actualización cotidiana a su vez anclada en matrices culturales e históricas, donde este calendario adquiere sus 'contenidos' específicos; por ejemplo para la construcción de categorías sociales definidas por la temporalidad: la ninez, la juventud, la adultez, la vejez [...]. (Reguillo, 2000, p. 96)

Os educadores supõem uma transição da infância à adolescencia e desta à vida adulta, mas a cumulatividade de fatos e/ou resultados que supõem no crescimento dos educandos é difuso e, parece-me, pouco registrado. Eventualmente, o desenvolvimento do educando é expresso em 
referência à noção empírica de emancipação, uma busca que ainda carece de delimitação coletiva, dado que o tratamento dessa questão se dá normalmente por diálogos orais, como os exemplos singulares dos educandos. Sendo o uso de registros escritos e de sistematizações uma prática não usual, em favor de um hábito de expressão e trocas orais. Mesmo a planificação realizada pela coordenação pedagógica restringe-se a planilhas compostas, sobretudo, por eventos.

A singularidade dos educandos, geralmente, é citada por meio dos casos de atendimento. Esses exemplos de vivências das crianças e dos adolescentes parecem referenciar sugestões para o planejamento do trabalho, sobretudo para os planos anuais. Numa dinâmica que aparentemente é dispersiva e demasiadamente pontual, a descrição de casos condensa indicadores do desejado pelos educadores, instigando mudanças/planos.

Poderia dizer que esses referentes vêm ao diálogo carregados de sentido e afetos, expressando ideais e categorizações que se compartilham e se compreendem desde o exemplo: seria uma base de compreensão, diálogo e expressão de idéias e sentimentos, indo, ademais, da catarse à construção de propostas. Diria ainda que o caso representa a singularidade numa busca por reconhecer cada educando em meio ao processo homogeneizador das metas de atendimento e dos grupos de oficinas.

[...] a gente está num trabalho assim de vincular algumas crianças com as educadoras. Nós temos um caso, que ele vai uma hora por semana (não obrigatória) à cozinha com as gurias [cozinheiras-educadoras sociais], para ajudar a secar a louça, cortar temperos. E não pelo fato das gurias precisarem dessa ajuda, mas pelo fato de ele se sentir importante, que ele não consegue no grupo [...]. (Márcia)

\section{E para problematização das práticas educativas}

Apesar de cada gestor trazer características singulares, que indicam importantes pontos de abordagem futura, nesse momento, enfatizarei al- guns aspectos gerais das narrativas. Assinalaria a recorrente referência à importância da educação e do trabalho e, sobretudo, a articulação discursiva 'estudar para trabalhar/obter ocupação' nas trajetórias, como tomadas de posição com vistas à socialização e à inserção social.

Nesse ponto, gostaria de recorrer às contribuições de Tardif (2000) quando afirma que, no caso do professor, "as etapas de sua socialização profissional não se dão em terreno neutro" (p. 224). Como hipótese, acredito que os coordenadores pedagógicos apresentam posicionamentos pessoais que aportam como referências pedagógicas na educação que postulam e que, em linhas gerais, está configurada na valorização simbólica da integração social (via família, religião, educação, trabalho) e na ênfase em relações assistenciais-educativas hierarquizadas e de proteção (afeto, acolhida).

Já no que concerne ao contexto de trabalho, a dimensão de 'acolhida' pode ser extendida ao conjunto das relações de trabalho no CPCA e, nesse sentido, pode significar (entre outras coisas) uma relevante estratégia da equipe frente ao convívio com a precariedade disposta pela pobreza e pela violência que permeia a vida dos educandos.

Ainda nessa hipótese, o predomínio de uma organização cíclica do tempo também poderia simbolizar "o possível a se realizar" frente ao dilema da difícil emancipação dos educandos e suas famílias: criar ambientes acolhedores e de proteção, mantendo crianças e adolescentes entre relações que possam oportunizar a socialização em tempos, hábitos, limites e, a partir daí, apostar na emancipação.

A problematização que, creio, poderemos encaminhar desde as informações que construímos sobre a articulação formação-tomadas de posição-contexto, pergunta por práticas mais participativas. Sem negligenciar a importância da constituição de vínculos educador-educando e a criação de ambiências amorosas (Maturana, 2000), há que se instigar a reflexão sobre as hierarquias que organizam o trabalho no CPCA. 
Assim, relativizar hierarquizações na gestão (pela condição de gênero) e na relação com educandos, propondo o estímulo à participação de crianças e adolescentes na organização de oficinas de aprendizagens ou na articulação de grupos de expressão identitária juvenil ${ }^{8}$. Enfim, problematizações que incrementem o exercício cotidiano de autonomia e participação, como alternativa reflexiva para construirmos nosso entendimento sobre a emancipação.

[...] necessita-se de práticas que veiculem, e não escondam, os conflitos e as contradições sociais, buscando solução para as mesmas, que permitam a construção de uma identidade coletiva a partir de valores fundamentais inscritos na história dessas pessoas, e que lhes permitam resgatar a dignidade e o poder no cerne das relações sociais. Mais do que isso, essas práticas devem ser capazes de reinscrever pessoas em uma filiação, em uma rede de pertencimento na qual elas se reconheçam e na qual elas possam ancorar projetos de futuro. (Nunes, 2005, p. 09)

\section{Considerações finais: para pensar os próximos passos}

0 contexto de trabalho dos educadores no CPCA e as relações que vêm estabelecendo com os educandos, conforme os dados que produzimos até o momento, desenham um ambiente perpassado mais recorrentemente por: valorização simbólica do estudo e do trabalho; convívio conturbador com a violência e a pobreza; tomadas de posição voltadas à acolhida e à proteção; desenvolvimento de atividades cíclicas e pautadas na interação com a singularidade (do caso); proposição de práticas socializantes e hierarquizadas na atividade educativa.

Procurando problematizar os temas sistematizados na primeira etapa da pesquisa, para continuar o trabalho, precisaremos observar as características que resumi neste texto não como elementos justapostos à realidade, mas como constituintes do contexto, com os quais o grupo organiza seu pertencimento ao trabalho de educar. Dialogando com a equipe e com cada gestor, há que se construir um caminho em conjunto, considerando as limitações que trazemos à investigação. Nesse sentido, não nos propomos a tratar todas as situações-problema que encontramos, mas poderíamos intensificar o processo reflexivo desde a noção de emancipação, como categoria e idéia-força que já vem mobilizando os educadores do CPCA.

Proporia três linhas de investigação: devoluções de sínteses das informações; elaboração de fluxogramas; e complementação do sociograma já construído. As devoluções de sínteses configuram novas entrevistas, nas quais os temas trazidos anteriormente pelo entrevistando são retomados, enfatizando as proposições contraditórias, para que o sujeito revise sua narrativa e construa novas formulações na sua relação, nesse caso, com os educandos.

Além de revisar os discursos elaborados, a devolução de citações literais dos educadores orienta-se para que estes visualizem seus dilemas narrativos, reorganizando-os e, talvez, buscando novas formas de atuar. Seria um exemplo, a princípio, a contradição presente no discurso do diretor geral da ONG: "curar os casos" versus "construir a aprendizagem junto com os educandos".

Outra linha, o fluxograma, trata-se de uma técnica que pode ser utilizada individual ou coletivamente para que se crie um discurso explicativo sobre os problemas do trabalho (no caso, a educação e a assistência a crianças e adolescentes). Trata-se do uso de uma planilha na qual se descrevem situações-problema do trabalho, tendo dois eixos de distribuição: nível de autonomia que o sujeito elaborador possui para resolver o problema e tipo de pro-

8. Para dar um exemplo, há grupos juvenis de Hip Hop que utilizam as dependências do CPCA para suas atividades, mas a ONG não acompanha ou incentiva a organização desses coletivos. Expressão identitária organizada por jovens, esses grupos poderiam aportar novas formas de atuação, em respeito aos saberes e pertencimentos construídos pelos coletivos de jovens-educandos.

9. Embora menos recorrente na fala de Pedro, a proposição de construção conjunta da aprendizagem também foi citada. 
blemas $^{10}$ (Socas, 2005). Na seqüência, priorizase quais seriam os problemas mais críticos e a relação entre eles no andamento dos serviços. Assim, podemos ter um registro (específico) de como pensam/explicam seu trabalho e dispomos, além disso, de uma base para formulação de propostas. Esse instrumento pode ser complementado e contrastado mediante consulta a outros sujeitos, que também atuam na comunidade e na mesma área assistencial-educativa.

Por fim, o complemento do sociograma passa por revisá-lo com os gestores e também por abri-lo aos demais educadores. Também se pode consultar outros sujeitos da comunidade para que ele seja representativo de um discurso o mais diverso possível. Novamente se caracteriza e contrasta a posição dos gestores.

Assim, temos ferramentas para refletir sobre as narrativas, hierarquizações e visões do trabalho e da comunidade já construídas. Nós, sujeitos da investigação, seríamos instigados a relativizar nossas tomadas de posição ao longo do processo e, ao mesmo tempo, teríamos ins- trumentos para planificar, conhecendo situações-problema consideradas mais relevantes e as potenciais parcerias para os serviços da ONG.

São possibilidades de continuidade que dependerão, sobretudo, do que o grupo construir e quiser fazer. As ferramentas estarão à disposição para que usemos ou não, conforme a mobilização da comunidade. Não temos uma solução para uma realidade tão precarizada, mas temos alternativas a trilhar rumo a uma nova auto-eco-organização de sujeitos e relações.

Assim temos configurado a investigação, com momentos de auto-reflexão de referências pessoais e profissionais, visando planificar relações e práticas diferenciadas, partindo do pressuposto de que o exercício cotidiano poderá contribuir para a formação dos educadores no trabalho, interferindo na interação educativa que estabelecem com crianças e adolescentes.

10. A tipologia de problemas poderia ser criada pelos próprios sujeitos, com base na primeira etapa da pesquisa. Villasante (2002) propõe quatro tipos básicos passíveis de serem considerados: tempo/tecnologia; economia/recursos; organização/política; e formação/cultura.

\section{Referências bibliográficas}

BATISTA, S. H. Formação. In: FAZENDA, I. (Org.). Dicionário em construção: interdisciplinaridade. São Paulo: Cortez, 2001, p. 135-140.

HOLZMANN, L. Notas sobre as condições da mão-de-obra feminina frente às inovações tecnológicas. Sociologias, n. 4, Porto Alegre, jul.-dez. 2000, p. 258-273.

IBGE. Amostra do censo demográfico. Rio de Janeiro, 2000. Disponível em: http://www. devinfo.info/brazilchildequity. Acesso em: 10 abr. 2006.

LINDÓN, A. Del campo de la vida cotidiana y su espacio-temporalidad. In: temporalidad. Barcelona: Antropos, 2000, p. 07-18.

(Coord.). La vida cotidiana y su espacio-

MARTíN, P. Mapas sociales: método y ejemplos prácticos. In: VILLASANTE, T. (Coord.). Prácticas locales de creatividad social. Madrid: El Viejo Topo, 2003, p. 91-114.

MORIN, E. A cabeça bem-feita. Rio de Janeiro: Bertrand Brasil, 2001.

. Epistemologia da complexidade. In: SCHNITMAN, D. F. Novos paradigmas, cultura e subjetividade. Porto Alegre: Artes Médicas, 1996, p. 274-286.

NUNES, M. Idiomas culturais como estratégias populares para enfrentar a violência urbana. Ciência \& Saúde Coletiva, Rio de Janeiro, v. 10, n. 02, p. 409-418, abr. 2005.

OLIVEIRA, C. de. Construindo a Lomba do futuro: projeto integrado de desenvolvimento sustentável da Lomba do Pinheiro. Porto Alegre: Prefeitura Municipal, 2004. 
RAMOS, S. Criminalidade e respostas brasileiras à violencia. Panorama Brasileiro - Observatorio da Cidadania-IBASE, Rio de Janeiro, 2004. Disponível em: http://www.ibase.org.br. Acesso em: 11 dez. 2005.

REGUILLO, R. La clandestina centralidad de la vida cotidiana. In: LINDÓN, A. (Coord.). La vida cotidiana y su espacio-temporalidad. Barcelona: Antropos, 2000, p. 77-93.

SALVARO, G. I. J. Jornadas de trabalho de mulheres e homens em um assentamento do MST. Revista Estudos Feministas, Florianópolis, v. 12, n. 01, p. 321-330, jan.-abr. 2004.

SOCAS, J. La técnica del fluxograma: apuntes desde la prática. In: VILLASANTE, T. (Coord.). Escola de Cidadania - textos. Porto Alegre: ONG Cidade, 2005, p. 40-62.

TARDIF, M. Saberes, tempo e aprendizagem do trabalho no magistério. Educação \& Sociedade, Campinas, ano XXI, n. 73, p. 209244, dez. 2000.

VILLASANTE, T. R. Redes e alternativas: estratégias e estilos criativos na complexidade social. Petrópolis: Vozes, 2002.

Recebido em 13.07.06

Aprovado em 10.04.07

Leandro Rogério Pinheiro é doutorando no Programa de Pós-Graduação em Educação (UNISINOS), em São Leopoldo/ Brasil. Em 2006, realizou estágio de doutorando na 'Universidad Complutense de Madrid'. 